A publication of the Muma College of Business | University of South Florida

\begin{tabular}{lcc}
\hline Volume 4 & Number 3 & 25 FEB 2019 \\
\hline
\end{tabular}

PETE HENDRICKSON, BRENDAN HESS, NIKKI JOSEPH, TOM NANKERVIS, RUSSELL STONE

\title{
HOW TO FILL THE HOLES IN MINING INVENTORY? ${ }^{1}$
}

\author{
How do I keep track of inventory in a decentralized and shifting setting?
}

JoAnn put down the inventory reports of four Mosaic mines that she had been contemplating. Much of the raw material for the company's phosphate fertilizer production was mined and processed at these Florida facilities. Keeping track of the vast array of equipment, parts, and supplies required to operate the mines had become an issue.

JoAnn Speaks, Purchasing Manager at Mosaic Company, was tasked in 2015 to implement a comprehensive system to identify, control and track the company's inventories. A recent Sarbanes-Oxley (SOX) audit had found weaknesses in Mosaic's inventory practices leaving it unable to adequately account for the disposition of millions of dollars of assets annually.

Working closely with technology companies Motion Industries and CribMaster ${ }^{\circledR}$, JoAnn had successfully implemented a radio-frequency identification (RFID) system at five Mosaic chemical facilities. The implementation experienced hiccups, but problems had been resolved and the benefits had quickly become apparent. Within two months of going live, losses were down 35\% and time spent locating items was reduced by 160 man-hours per month at the pilot chemical facility.

Once the chemical facility implementation process approached completion, JoAnn turned her attention to the mines. RFID was great for the static and centralized chemical facility operating structure, but would it be successful in the mines? Although each mine had a central warehouse facility, equipment and numerous inventoried, critical-to-operations components were also spread across many square miles to minimize downtime in the event of a failure. This created environmental and connectivity issues that would have to be overcome to use RFID. With all the additional options available outside of RFID including vending, inventory centralization and even manpower additions, what was going to be the right single or combination of solutions? Or, was there something she hadn't yet considered? The only sure thing was the SOX audit meant the status quo was not an option.

JoAnn picked up the reports and leaned back in her chair as she considered the strengths and weaknesses of the possible solutions and decided what to do next.

\footnotetext{
${ }^{1}$ Copyright @ 2018, Pete Hendrickson, Brendan Hess, Nikeisha Joseph, Thomas Nankervis, Russell Stone. This case was prepared for the purpose of class discussion, and not to illustrate the effective or ineffective handling of an administrative situation. Names and some information have been disguised. This case is published under a Creative Commons BY-NC license. Permission is granted to copy and distribute this case for non-commercial purposes, in both printed and electronic formats.
} 


\section{The Phosphate Rock Industry}

Phosphorus is a solid, non-metallic element crucial to all living things. It did not occur naturally in its pure, uncombined state. Instead it was found in chemical compounds known as phosphates. Those phosphates were concentrated in phosphate rock deposits around the world.

Three macro-nutrients were critical to plant growth; nitrogen $(\mathrm{N})$, phosphorus $(\mathrm{P})$, and potassium (K). These elements were combined to form NPK fertilizer. The phosphorus in NPK fertilizer was in the form of phosphates and 90\% of global phosphate production was utilized for fertilizer production (PotashCorp, 2016). The remainder was primarily used in animal feed and industrial processes.

Humans had used organic fertilizers such as manure for thousands of years, however, the large-scale agriculture necessitated by a growing population required the use of synthetic, mineral fertilizers. During the $20^{\text {th }}$ century, the world's population exploded from 1.65 billion to 6 billion (Worldometers, 2017). According to the International Fertilizer Development Center, "about half of the world's population is alive today because of increased food production fueled by mineral fertilizers (IFDC, 2017). So, although phosphates were not as glamourous as gold or silver it was hard to overstate their importance.

\section{Mining and Processing}

Phosphate deposits originated as fossil remains laid down on sea beds millions of years ago. Most phosphates were obtained from open pit mines where dragline excavators removed overlying materials to expose the phosphate ore. The removed materials were used to reclaim previously-mined land. The phosphate ore was then moved by conveyor belt or truck or mixed with water and pumped to a processing facility, known as a beneficiation plant, for purification. The ore went through a series of screening, washing, floatation, and drying processes to separate waste materials from the phosphate rock. The phosphate rock was then sent to manufacturing plants for transformation into finished products.

\section{World Reserves, Production, and Key Players}

According to the United States Geological Survey (USGS) 2017 Mineral Commodity Summaries (n.d.), the total amount of global phosphate ore was about 300 billion tons. Exhibit 1 shows the global distribution of the 68 billion tons of that amount that was considered economically recoverable given current technology (Jasinski, 2017). The USGS report showed that phosphates were heavily concentrated in the Morocco and Western Sahara region, which held 74\% of the world's reserves. The remainder was spread in smaller pockets around the globe.

Although Morocco and Western Sahara held the majority of reserves, its 30 million metric tons (MT) production in 2016 trailed China's 138 million MT. The United States was the third leading producer with 27.8 million metric tons. Mines in Florida and North Carolina accounted for more than $75 \%$ of U.S. production with Idaho and Utah accounting for the rest (Shaw, 2017). China, the United States, Russia, India, and Brazil were the leading phosphate rock consumers.

Key players in the global phosphate market included Mosaic (USA), OCP Group (Morocco), Potash Corp, MBAC Fertilizer Corp, and Agrium Inc. (Canada), Wengfu Group and Sterling Group Ventures Inc. (China), Anglo American (South Africa), Grange Resources and Shaw River Manganese Ltd (Australia), and PhosAgro (Russia).

\section{Industry Performance and Outlook}

Phosphate rock was a commodity so the world market determined its price. Since phosphates were primarily used to produce fertilizers, phosphate demand was largely dependent on fertilizer demand. An 
imbalance between supply and demand caused phosphate rock prices to spike to unprecedented levels in 2007 - 2008 (see Exhibit 2 for historical phosphate rock price data). The high prices, along with the global financial crisis then caused demand and prices to crash. After a slight recovery in 2012 phosphate rock prices trended steadily down. The downward trend was driven by a variety of factors including excess supply, taxes imposed by the Chinese government, and companies seeking market share at the expense of profit maximization.

By 2017 conditions looked right for an increase in demand for phosphate rock. The United Nations Department of Economic and Social Affairs projected that the world's population would increase by over $50 \%$ to 9.7 billion by 2050 (UN DESA, 2015). To feed that many people a dramatic increase in food production would be required and that would lead to an increase in the demand for phosphates. Additionally, increased production of biofuels and dietary shifts in developing countries from vegetarian to increased consumption of meat would increase demand for animal feed, another product using phosphates.

Although phosphate demand seemed primed to increase, it was not clear that increasing demand would translate to improved financial performance in the near-term since the increased demand would be at least partly offset by the opening of new mines in North Africa and the Middle East and by increased production by China and Morocco. Additionally, the phosphate rock industries in those countries were largely state-owned raising the potential of prices driven by political, rather than the market, factors.

Another source of uncertainty was the environmental impacts of phosphate mining and processing. The strip mining process disrupted the landscape. Surface and groundwater quality could be adversely affected by erosion and leaching of toxic substances like radium from the materials removed from the mine. Phosphates themselves could cause significant environmental damage if allowed to enter bodies of water. Their presence could prompt overgrowth of aquatic vegetation and the reduction of oxygen levels which could be fatal for fish. These issues had been long recognized and mostly addressed in developed countries. Growing awareness begun to drive increased regulation of the industry in emerging economies like China. The cost of addressing environmental issues could hasten the shift of production from the current leaders to developing countries that had both less regulation and the bulk of world phosphate reserves.

Taken together the result of these factors was an industry facing an uncertain outlook.

\section{Long-Term Issues}

Phosphorus was an element so could not be created or destroyed. However, existing deposits took millions of years to form so readily-accessible phosphorous was a finite resource. There were many contradictory timelines, but it was clear that within 100 years the world would reach "peak phosphorous," the point when global phosphorus production was at its greatest. After the peak, phosphorus production would enter a permanent, slow decline as it took progressively more effort and resources to extract and refine remaining deposits. This would result in decreased phosphorus availability and, because phosphorus was necessary for plant growth, reduced crop productivity. Since this would occur concurrent with a rapidly increasing population it would set the stage for potentially disastrous food shortages. The phosphate industry would ultimately have to adapt to address decreasing available deposits. Undiscovered reserves would need to be located and techniques would need to be devised to maximize utilization of existing resources until more permanent solutions were developed. 


\section{Mosaic Company Overview}

Mosaic, a fortune 500 company based in Plymouth, Minnesota, formed in 2004 through the merger of Cargill's crop division and IMC Global. In 2014 it acquired CF Industries and Archer Daniels Midland Company’s fertilizer divisions. With annual revenues in excess of \$7 billion and over 9,000 employees operating in eight countries, it was one of the world's largest producers of phosphate products. Its 5.3 million tons of phosphoric acid and approximately 17.2 million tons of phosphate rock were sold in the United States and globally through its own distribution channels. Additionally, Mosaic operated five Potash mines in North America with an annual capacity of 10.5 million tons accounting for $12 \%$ of the global market share.

At $83 \%$ of global market share, Mosaic was a much more dominant player in phosphates. It mined over 200,000 acres throughout Central Florida and processed phosphate from these mines and from mines it owned in South America, at 6 facilities in Florida and Louisiana. These operations accounted for over $65 \%$ of its annual revenue.

Mosaic's primary products, phosphate, and potash were commodities that could readily be mined and processed by competitors presenting a perpetual threat to the business. The commodity-dependent business model operated on margins that were dictated by published market pricing and the cost per ton to produce was driven by fixed costs associated with owning and operating major facilities. This reliance on commodity pricing and external market supply and demand resulted in a $48 \%$ reduction in net sales year over year in 2016 when markets dictated a dramatically lower selling price for phosphates and potash.

Mosaic had made strengthening its global distribution network a stated strategic initiative. Mosaic's International Distribution segment had recently been spun off into its own operating unit providing the firm a competitive advantage in reaching global markets. Efficient distribution would help Mosaic drive the volume needed to differentiate on pricing and shelter the bottom line from exposure to commodity pricing.

\section{Technology}

\section{Radio-Frequency Identification (RFID)}

Radio frequency identification, or RFID, was a generic term used to describe a system that identified objects or persons through a unique serial number using radio wave technology (Violino, 2005). RFID technology leveraged a system that included a tag or label, a type of reader, and one of a variety of frequency bands (LF, HF, UHF, or Microwave) of radio frequency communication (Exhibit 3).

RFID tags were placed on the objects to be tracked. RFID readers emitted interrogating radio waves. RFID tags were either passive or active. Passive RFID tags contained two core parts: an integrated circuit for storing and processing information, and an antenna to receive and transmit a signal. The antenna collected the radio energy from the RFID reader and used it to power up, access its stored information (usually a unique serial number, stock number, production date or other specific information), then transmitted it back to the reader in response to an interrogating signal. Active RFID tags featured an onboard battery in addition to the integrated circuit and antenna and were capable of periodically transmitting their credentials, much like a beacon (Mushtaq, 2017).

RFID Readers could be either passive or active. Active readers transmitted interrogation signals and received authentication responses from passive RFID tags. Passive RFID readers received radio signals from active tags. Readers could be fixed or mobile meaning, simply, they were set up to control a specific 
interrogation zone or were hand-held or mounted on a vehicle so the reader could be moved about. RFID systems were generally defined by the type of tag and the type of reader. A Passive Reader Active Tag (PRAT) system, for example, had a passive reader and used active tags while an Active Reader Passive Tag (ARPT) system used active reader interrogations to capture authentication responses from passive tags. (Mushtaq, 2017)

Basic RFID technology dated to World War II when the Allies leveraged Identification, Friend or Foe (IFF) Transponders to identify friendly or adversary aircraft without direct communications. True RFID, as it was then known, dated to the invention of passive RFID. In the first RFID patent filed in 1970 (Exhibit 4) Mario Cardullo (1970) described the technology as:

A novel transponder apparatus and system is disclosed, the system being of the general type wherein a base station transmits an "interrogation" signal to a remote transponder, the transponder responding with an "answerback" transmission. The transponder includes a changeable or writable memory, and means responsive to the transmitted interrogation signal for processing the signal and for selectively writing data into or reading data out from the memory. The transponder then transmits an answerback signal from the data read-out from its internal memory, which signal may be interpreted at the base station. In the preferred inventive embodiment, the transponder generates its own operating power from the transmitted interrogation signal, such that the transponder apparatus is self-contained. (USA Patent No. US3713148 A, 1970)

RFID tags were the same technology used in the U.S. e-Passport, the security tags on merchandise at a retail store that activated as shoppers passed through the exit, access badges, tracking library books, and even in the numbers worn by participants in marathons and other races that captured completion times.

RFID technology in inventory control was a key capability. RFID inventory control systems were comprised of tags, readers, and software to log events. RFID technology allowed inventory control of small items, such as tools, entering and leaving a drawer system or tracking power tools coming and going from a storeroom. This technology worked through passive UHF tags placed on the tools paired with active readers that tracked the tools entering and leaving either the toolbox or the storeroom and directly reported inventory status to the tracking software system. The use of RFID was further enhanced by person-specific RFID badges that assigned each tool taken or returned to a specific user.

\section{Industrial Vending Machines}

Industrial vending was the use of assorted sizes and shapes of modernized vending machines to make inventory available to personnel at the point of use while maintaining an accurate count of inventory levels. This was accomplished by leveraging a combination of multiple data elements including the vending machines, unique badge-specific identifiers, software tracking and accounting, and sometimes RFID.

There were several vending machines types such as carousel, coil, divided drawer, lockers, and weightsensitive storage bin systems capable of dispensing various stock and inventory items (Exhibit 5). Coil vending machines used a rotating coil, like candy dispensing vending machines that rotated and pushed forward until a single item dropped out for use. Carousel vending machines had rotating carousels with inventory slots which rotated to the specific selected item. Divided drawer vending machines had locked drawers that pulled out. Within each drawer were a variety of different containers separately locked as 
HENDRICKSON, HESS, JOSEPH, NANKERVIS, STONE

well. Locker vending machines had a locker or post-office-box sized, separately locked lock boxes. Weight sensitive storage bins tracked inventory by the bulk weight present.

Vending machines relied on a real-time software system to track the quantities located within the various vending solutions. This required interconnected vending machines and internet or intranet access for the machines to communicate with the central software service. The software allowed for dispersed vending machines at the point of use to communicate inventory levels in real time to centralized warehousing.

Badging systems could connect the inventory taken or replaced at the various vending locations to specific employees through the issuance of a RFID reader badge with a unique identifier for each employee. To provide additional data or control, badges and inventory could also be restricted by type and quantity to specific roles or individuals.

Vending machines that disbursed reusable equipment, such as hand tools, could be paired with RFID technology where the items were also individually tagged with RFID tags or labels. This was best used with vending solutions that allowed the removal and replacement of inventory.

\section{Mosaic Inventory}

After the SOX audit, Mosaic made a concerted effort to determine why its actual inventory differed from its records since, before developing solutions, it needed a good understanding of the problem. Many potential causes were investigated including items stored in incorrect locations, transaction recording errors, and misread stock numbers. Ultimately most of the discrepancies were attributed to organizational and procedural issues. The investigations major findings were laid out and Mosaic began to develop solutions.

\section{Mosaic Inventory Processes}

Mosaic warehousing facilities consisted of seven chemical and nine mining facilities located in Louisiana, Florida, New Mexico and Canada. Each facility operated differently from the others. Inventory control processes were not standardized throughout the different locations.

The Maintenance organization was the primary customer for the warehouses. Therefore, the local warehousing process was dictated by its site maintenance organization. The processes and warehouse setup were determined by the site to best fit maintenance needs.

Most warehouses had issue windows in which there was a person tasked with assisting maintenance to issue out parts from the warehouse. The chemical warehouses were manned during the day, but at night and on weekends, there was no one facilitating the issuing of material in and out of the warehouse. This after-hours lack of personnel led to many items being removed from the warehouse without proper or any documentation. In addition, the warehouse operations were contracted, third-party companies. If a person from one warehouse had to work at a different location, the process was different which hindered operations.

\section{Mosaic Inventory Issues}

The inventory issues at Mosaic were attributed, but not limited to, three major factors: stock-outs, misplaced or lost inventory and cycle count discrepancies. 


\section{Stock-outs}

Stock-outs were a major concern as they caused issues with the maintenance organization not having the parts necessary to do its job. One major cause of stock-outs was end users removing items from inventory without properly recording the removal in Maximo ${ }^{\circledR}$, the inventory control system. Inventory was based on stock levels. Items were set up with minimum, maximum and safety stock levels. When an item reached its minimum or safety stock level, the system would trigger a reorder of that item to replace the item in inventory. If an end user failed to properly issue an item out of inventory, the inventory levels did not reflect the adjusted number so the reorder was not triggered causing the item to be unavailable. During the hours when the warehouses were unmanned, attributed to items being removed from inventory without a proper account in the system which then resulted in a stock-out.

\section{Misplaced Inventory}

Mosaic's inventory contained repairable spares. These consisted of items which were removed from stores for either application-use or to be repaired and then returned to the warehouse. The warehouse experienced issues with not being able to locate repairable spares since often times, these items were issued out of inventory but not returned. It could take warehouse personnel 20-40 weeks to track down an item's location and return it to the warehouse.

\section{Cycle Count Discrepancies}

Warehouses had physical count issues as the counts of inventory on the shelves did not match the counts in Maximo®. Random audits uncovered items of inventory missing with no accountability of where those items were used or expensed to. This caused a loss of inventory value which resulted in an unbalance in inventory reconcilement.

\section{Inventory Solutions}

These warehouses contained over 10,000 different types of items. In order to manage inventory counts effectively, cycle counts were an important part of the process. This was an auditing process in which inventory was counted on a routine basis. Mosaic reviewed three different methods' effectiveness on conducting inventory counts: manual, barcodes and RFID tracking.

\section{Manual Cycle Count}

The manual cycle count process involved a routine schedule in which specific areas of inventory were physically counted on specified days and the counts were reconciled in the system. The issue with this process was that an area could take a whole cycle before being counted again. Therefore any missing inventory would not be caught immediately.

\section{Barcodes}

Barcode solutions typically consisted of hardware and software systems that operated on computers and mobile devices. The material was labeled with unique barcodes (SKU) which contained inventory counts in the system. The user would scan an item's barcode when a part was issued out of inventory. Although barcodes were a bit more efficient and automatic than physical reconciliation, they still required manpower to scan the barcodes to conduct a cycle count. 
HENDRICKSON, HESS, JOSEPH, NANKERVIS, STONE

\section{RFID Implementation Project}

In Exhibit 6 (Mosaic slide of RFID count effectiveness) the inventory count accuracy using RFID technology was approximately $95 \%$ with half the time to conduct a count when compared to doing it manually or using bar codes.

Following the results of the SOX audit in 2015, Procurement worked with Motion Industries to come up with a solution to its inventory issues. Motion designed a RFID tracking system setup for the chemical inventory warehouses. The first phase was to focus on improving chemical facility warehouse operations. The pilot facility chosen to start the project was Louisiana, which JoAnn managed. The solution involved a total redesign of the warehouses. Mosaic hired an inventory specialist company to help assess the current inventory setup. The inventory specialist company conducted an efficiency study to help optimize material placement in the warehouse and help inventory personnel move inventory in a more efficient and effective way. Faster moving items were placed in closer vicinity to the inventory keeper.

State-of-the-art portal technology was then installed in key areas of the warehouses. Mosaic's IT department worked with CribMaster ${ }^{\circledR}$ to integrate with Maximo ${ }^{\circledR}$. Once this integration was functional, LPR (License Plate Recognition) systems were installed at every exit around the warehouse. The materials were held in fenced and gated areas which were accessible by ID scan. The material was then bagged and tagged with RFID controls. The process for preparing material was to bag and/or tag items stocked in inventory with the RFID tags or labels. This allowed tracking of all items that left the warehouse. Maintenance personnel scanned IDs prior to admittance into the warehouse and upon exit and any material leaving the warehouse was tracked to that individual or department. Maintenance personnel and warehouse contractors were all trained on the new process and systems.

There were a few challenges that appeared once the project started at the chemical warehouse. Since every item delivered to the warehouse required appropriate bagging and tagging, the warehouse receivers experienced an overflow of items on a daily basis. Mosaic needed a way to make this process move faster so that the items delivered were packaged and stocked in a timely manner. Mosaic began to work with its alliance partners to arrange pre-packaging and tagging at the supplier's site prior to delivery. Since $80 \%$ of its suppliers were alliance partners, this significantly decreased the workload for the warehouse receivers. Additionally, Mosaic created a specific delivery schedule for its suppliers. Suppliers were given specific times and days for deliveries to keep inflows at a manageable level.

Electrical outages were another concern. Since these RFID systems were all electronic, an outage would cause a system shutdown that would prevent maintenance personnel being able to issue items out of inventory through the system. Although outages were often resolved quickly during normal operating hours, an outage during the night or over the weekend could result in items being removed without being accounted for.

Although the RFID technology had several kinks to work out, the benefits started to become apparent. The RFID systems started to help the chemical warehouses gain efficiency and accuracy in the process. The Louisiana facility, after following the new process, experienced a noticeable change in inventory accuracy after $90 \%$ utilization of the CribMaster ${ }^{\circledR}$ RFID system. Stock-outs dropped from $20-25 \%$ to around 2\%. Man-hours used to track missing inventory decreased by 160 hours per month. The new system was then placed in additional warehouses with another warehouse going live every two to three months. It took about 18 months to fully implement the RFID system at five of seven chemical warehouses. 


\section{Mining Facilities}

The next phase was to implement an inventory control system at the mining facilities. Mosaic had five mining facilities in Florida, one in New Mexico and three in Canada. In addition to the standard inventory issues experienced at the chemical facilities, the mining facilities had other concerns on having the right parts within access to do the job, with minimal interruption to production.

At the chemical facilities inventory was static and in one location; however, the mining operations were different. Mining personnel was constantly mobile. Mining workers operated machines to dig out ores from the ground. Mining operators' productivity performance was determined by how many 'scoops' of ore they completed a work cycle. There was a need to have maintenance parts readily available to keep the equipment running in order to prevent a failure which could result in lost production time.

The maintenance material was located in portable buildings. These portable buildings were sometimes located 20 minutes to an hour from the mining locations. Crews were responsible to pre-kit material based on a parts list submitted by planning for each job scheduled. Mining operators retrieved these kits at the portable facility prior to going to the mining locations. It was important that the right material was in each kit to avoid operators having to return to the buildings to retrieve missing parts. Due to the distance of the buildings, this could result in hours of delay and lower productivity for the mining operations. One major recurring issue was 'simple parts' (i.e. fasteners, bolts, screws, etc.) being left out of the kits.

The mining operations needed a model designed for its mobile setup to ensure the material was readily accessible to the mining operators. The mining manager told JoAnn, "If you want to really help me, keep my operators on that machine equipped with the parts they need.” Mosaic tasked Motion Industries to come up with a model to better serve the mining operations.

\section{The Decision}

JoAnn knew that to make this phase of the project successful she would have to work closely with the individuals who would be using the inventory daily. As with many technological processes, there were pluses and minuses to the various options she had before her and in order to pick the right one or combination would also require buy-in from the sites. The solution had to meet financial constraints, but also not be so intrusive to everyday operations that it created an impediment for the sites.

So, after many discussions with site personnel, Motion Industries and CribMaster ${ }^{\circledR}$, Jo Ann and the team had developed the following options:

1. Centralize all inventory from the remote areas to the site warehouse and implement the exact RFID technology as used at the chemical sites there. The exact cost (Exhibit 7) of such a project was easy to quantify and would fit within the fiscal year's capital budgeting estimates. This would however require the consolidation of numerous field locations for each mine site and could increase downtime while retrieving needed equipment and parts from the central location.

Personnel required to run this operation would be decreased, which was a large potential cost savings. As discussed above there could be an increase in downtime due to waiting and that may have to be offset by adding personnel for the purpose of driving parts to the field, therefore any efficiencies gained could potentially be lost. 
HENDRICKSON, HESS, JOSEPH, NANKERVIS, STONE

The security and accountability issues identified in the audit would be covered by this option, but the overall impact to operations was not fully known until implemented.

2. Bring back the previously used vending machine options and deploy them throughout the facilities for high turn items. As this had not been a successful project by the previous implementing vendor, it was a risk to Mosaic to try this again without additional reassurances and resources from Motion. Motion does have the expertise required to support such an endeavor, but the revenue generation would need to be in line with requirements to maintain.

Vending would not cover the large items typically stored in the warehouses, but it would provide some level of security and accountability that was currently needed based on the SOX findings. Larger items would still require consolidation or some other enhanced controls.

3. Continue with the current practice and hire additional personnel to better control, track and maintain inventory in the warehouses and field storage sites. This had the most long-term cost of all the options as there was no end to the cost of adding and maintaining personnel. There was also the fact that there were no gained efficiencies and accuracies in this option.

This would be the quickest to implement and would require no capital funds. It would enhance the current practices and potentially cover the issues identified in the audit.

4. Develop a site specific combination using key parts of the RFID systems as well as vending. This approach had not been tried yet by Mosaic, but Motion had other customers who they had implemented such projects. While this would not be the cheapest option, it would cover the majority of the audit issues as well as have some cost savings to Mosaic.

Each option would require training of inventory personnel and a with the exception of option 3, would also require training of all site personnel. This would mean that operations would be impacted during those training times, but with a rolling schedule that could be minimized. Options $1,2 \& 4$ were also major changes to inventory management process and as such could face some degree of resistance at the site level. However, those same options would greatly increase inventory management operation's efficiencies as well as security and accountability for the entire plant.

All equipment and personnel could easily be moved from site to site as operations expanded or shrank. In the case of shrinkage, unlike the equipment, personnel could be reduced to account for that reduction. Implementation time for Options 2, 3, \& 4 were relatively equal, while Option 1 would require additional time to conduct the redesign of the warehouse.

As Jo Ann weighed the options she thought about what had been had accomplished in the warehouses thus far. Her boss was still driving the team to give the company more in terms of inventory controls and she knew this next phase was even more important than the previous. Making the right decision would not be easy as it would require compromise from all parties as they moved to change current controls. What was the right single or combination of options for the continued success of improving inventory management? 


\section{References}

Cardullo, M. (1970). U.S. Patent No. US3713148 A. Washington, DC: U.S. Patent and Trademark Office.

Engel, R. J. (2006, May). Sarbanes Oxley Impact on Supply Chain Management (91st Annual International Supply Management Conference, 2006) [Abstract]. Retrieved March 7, 2018, from https://www.instituteforsupplymanagement.org/files/Pubs/Proceedings/HCEngel.pdf

IFDC (2017). Fertilizer technology development. (2017, December 05). Retrieved July 31, 2017, from https://ifdc.org/fertilizer-technology-development/

InfoMine (2018). Historical phosphate rock prices and price chart. Retrieved March 28, 2018, from http://www.infomine.com/investment/metal-prices/phosphate-rock/all/

Mineral Commodity Summaries. (n.d.). Retrieved August 22, 2017, from https://minerals.usgs.gov/minerals/pubs/mcs/

Mushtaq, N. (2017, April 26). RFID Radio Frequency Identification. Retrieved from CCTV Institute. Retrieved August 30, 2017, from http://cctvinstitute.co.uk/rfid-radio-frequency-identification/

Violino, B. (2005, January 16). What is RFID. Retrieved September 2, 2017, from http://www.rfidjournal.com/articles/view?1339

PotashCorp (2016). What we do. Retrieved September 03, 2017, from http://www.potashcorp.com/irc/company/overview/overview-operating-environment/phosphateoverview

UN DESA (2015, July 29). World population projected to reach 9.7 billion by 2050. Retrieved August 30, 2017, from http://www.un.org/en/development/desa/news/population/2015-report.html

\section{Acknowledgements}

This case discussion research was completed by this team of MBA students in the MUMA College of Business at the University of South Florida with significant support and contributions by JoAnn Speaks Purchasing Manager at The Mosaic Company. 


\section{Biography}

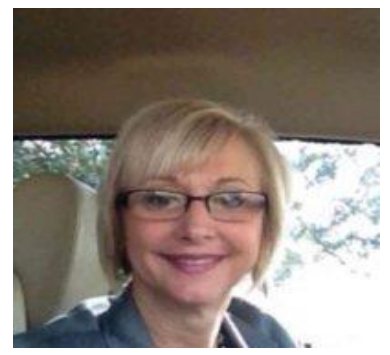

JoAnn Speaks is the Purchasing Manager for The Mosaic Company, world's largest P\&K Producer. Her career launched in 1987 in Procurement and Warehouse management. Working for a company in a highly competitive, ever changing commodity market has given Speaks the opportunity to work and excel in unique and innovative platforms. This ranged from negotiating multimillion dollar contracts to cutting edge technology projects to meet Mosaic's strategic vision. Speaks draws on her experience and passion for Procurement to push beyond the traditional limits, introducing new cost saving strategies and culture changing initiatives.

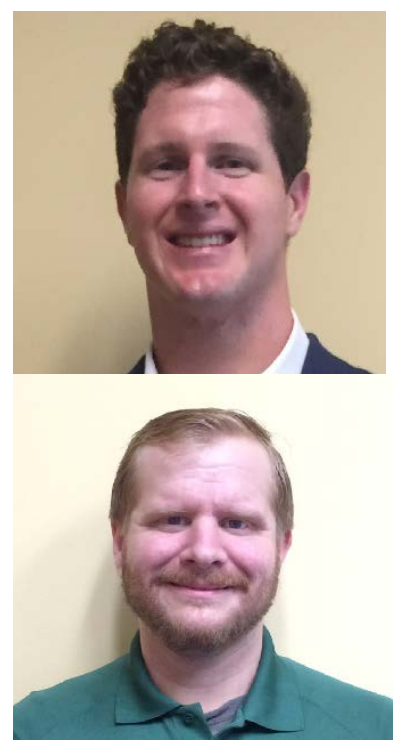

Peter Hendrickson graduated from Tulane University in New Orleans in 2010 with a bachelor's degree in management. Hendrickson works as the national account manager at Rehrig Pacific Company. He collaborates with executives in the beverage industry to reduce operating costs, enhance sales margins and increase employee retention. He has been the national account manager since 2015. Prior to that, he was the territory sales manager with the same company.

Brendan Hess received a bachelor's degree in multidisciplinary studies from Liberty University in Lynchburg, Virginia, in 2012. He also earned a certificate in criminal justice intelligence studies the same year from the University of Maryland in College Park, Maryland. Hess is the regional business manager for Far Ridgeline Engagements. In this role, he provides business development, marketing, program management and project development services for a variety of commercial and government organizations. His background is in risk management, operations, investigations, analysis and training.

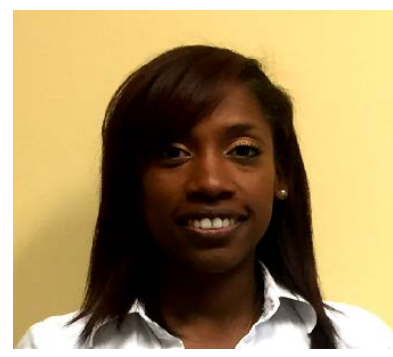

Nikeisha (Nikki) Joseph received a bachelor's degree in electrical engineering in 2003 from the New Jersey Institute of Technology in Newark, New Jersey. Joseph rose in the ranks at Gerdau North America to an executive level position in just five years. She now is the senior category manager, which means she oversees efforts to procure and provide engineered products used in manufacturing plants that increase productivity and at the same time, reduce working capital.

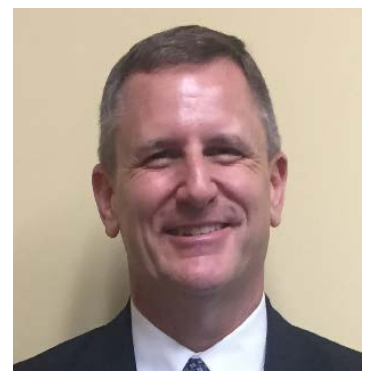

Thomas Nankervis graduated in 1985 from the University of Tennessee in Knoxville, Tennessee, with a bachelor's degree in communications. He earned a master's degree in management in 1989 from Lesley University in Cambridge, Massachusetts. Nankervis is laboring to bring the world together. Nankervis is headquartered at the U.S. Central Command at MacDill Air Force Base, where he manages the Wales Initiative Fund for the government. Incorporating guidance from the Office of the Secretary of Defense, Nankervis prepares annual program goals, aligning those with U.S. strategic doctrine. In all, he is involved in about 300 events a year and oversees a budget of about \$7 million. 


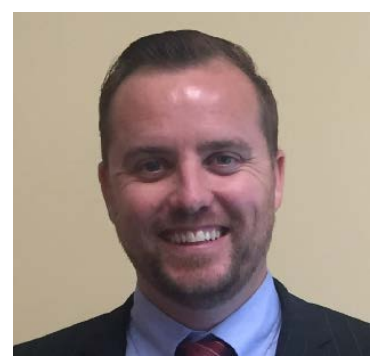

Russell Stone received a bachelor's degree in nuclear engineering technology in 2008 from Thomas Edison State College in Trenton, New Jersey. Stone is the compliance manager with Motion Industries and he ensures implementation and completion of mission and time-critical projects. Prior to joining Motion Industries, Stone worked for MetalTek International, a corporation that provides metal fabrication services for nuclear utility companies. His military experience, serving as a nuclear quality assurance supervisor, mechanic and instructor in the U.S. Navy, also helped guide his path. He earned a Project Management Professional certification through the Project Management. 


\section{Exhibit 1: Global Economically Recoverable Phosphate Reserves}

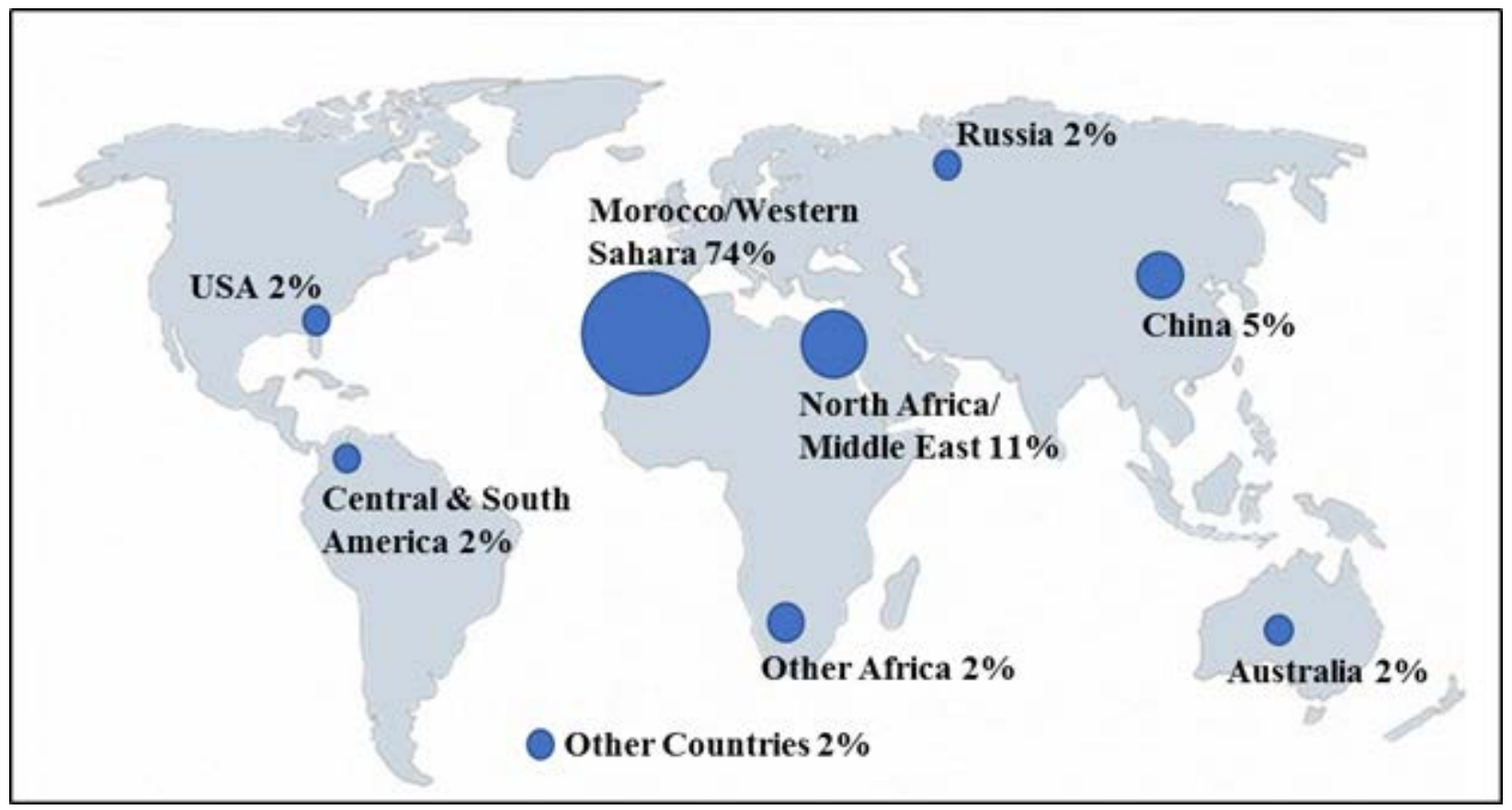

\begin{tabular}{|l|r|r|}
\hline \multicolumn{1}{|c|}{ Country/Region } & Reserves (Tons) & \multicolumn{1}{c|}{ Percentage } \\
\hline Australia & $1,100,000,000$ & $2 \%$ \\
\hline $\begin{array}{l}\text { Central and South } \\
\text { America }\end{array}$ & $1,170,000,000$ & $2 \%$ \\
\hline China & $3,100,000,000$ & $5 \%$ \\
\hline Morocco WS & $50,000,000,000$ & $74 \%$ \\
\hline N Africa/ME & $7,310,000,000$ & $11 \%$ \\
\hline Other Africa & $1,580,000,000$ & $2 \%$ \\
\hline Other countries & $1,165,000,000$ & $2 \%$ \\
\hline Russia & $1,300,000,000$ & $2 \%$ \\
\hline US & $1,100,000,000$ & $2 \%$ \\
\hline TOTAL & $\mathbf{6 7 , 8 2 5 , 0 0 0 , 0 0 0}$ & $\mathbf{1 0 0 \%}$ \\
\hline
\end{tabular}

Source: U.S. Geological Survey, Mineral Commodity Summaries, January 2017 


\section{Exhibit 2: Phosphate Rock Price History}
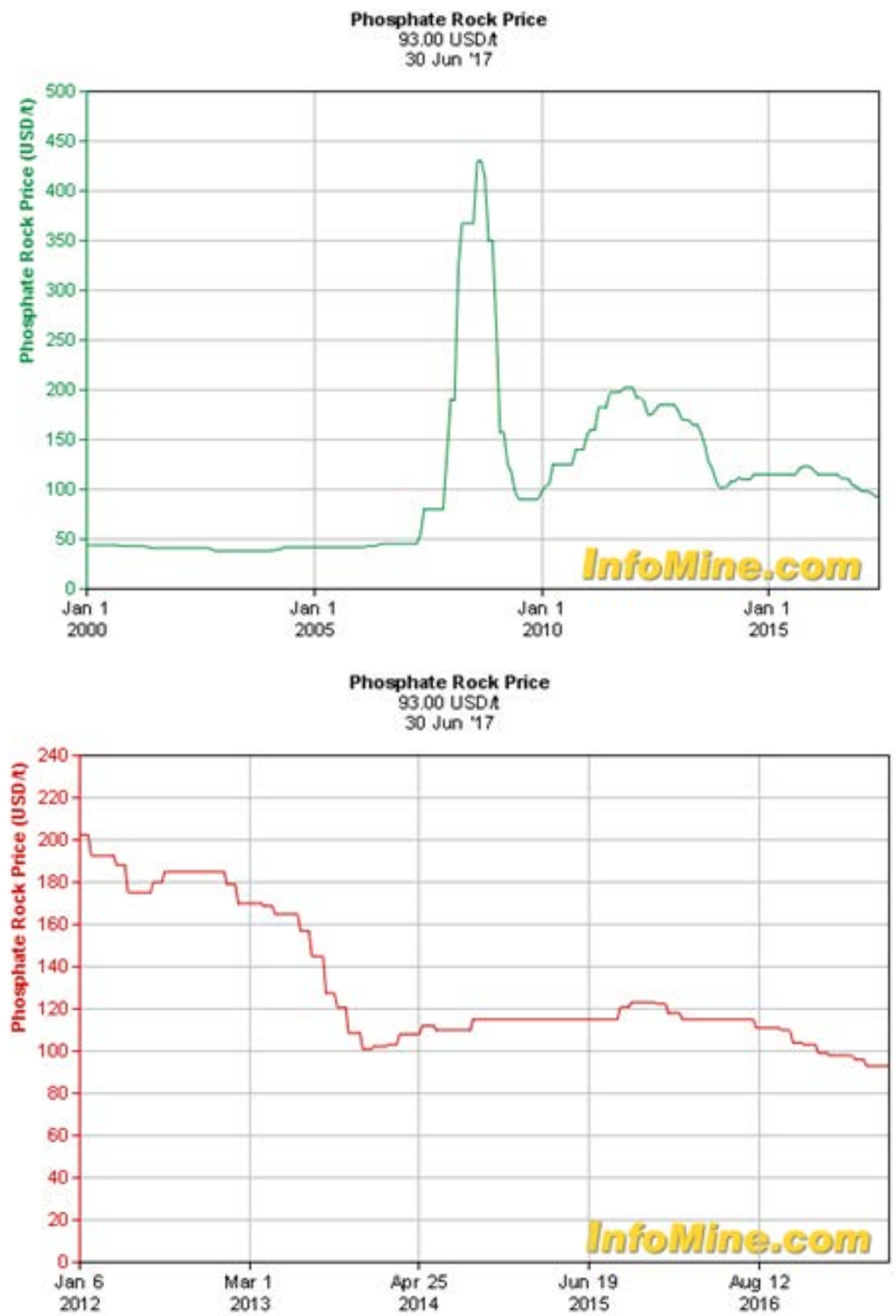

Source: InfoMine (2018). Retrieved from http://www.infomine.com/investment/metal-prices/phosphaterock/all/ 


\section{Exhibit 3: RFID Frequency}

\section{BAND}

$120 \sim 150 \mathrm{KHz}$

$13.56 \mathrm{MHz}$

$433 \mathrm{MHz}$

$865 \sim 868 \mathrm{MHz}$

$902 \sim 928 \mathrm{MHz}$

$2450 \sim 5800 \mathrm{MHz}$

$3.1 \sim 10 \mathrm{GHz}$

\section{TYPE}

Low Frequency

High Frequency

Ultra High Frequency

Ultra High Frequency

Ultra High Frequency

Microwave

Microwave

RANGE
$10 \mathrm{CM}$
$10 \mathrm{CM} \sim 1 \mathrm{M}$
$1 \sim 100 \mathrm{M}$
$1 \sim 12 \mathrm{M}$
$1 \sim 12 \mathrm{M}$
$1 \sim 2 \mathrm{M}$
$\sim 200 \mathrm{M}$

Class 1 UHF /HF, WORM ( Write Once, Read Many)

Class 3 Semi-Passive or Active $\mathrm{R} / \mathrm{W}$ with onboard sensors and parameters like temperature etc.

Class R/W active tags with built- Class 5 Can Power to other tags and 4 in transmitters and communicate with other tags \& readers. 
Exhibit 4: Transponder Apparatus and System Image (USA Patent No. US3713148 A, 1970)

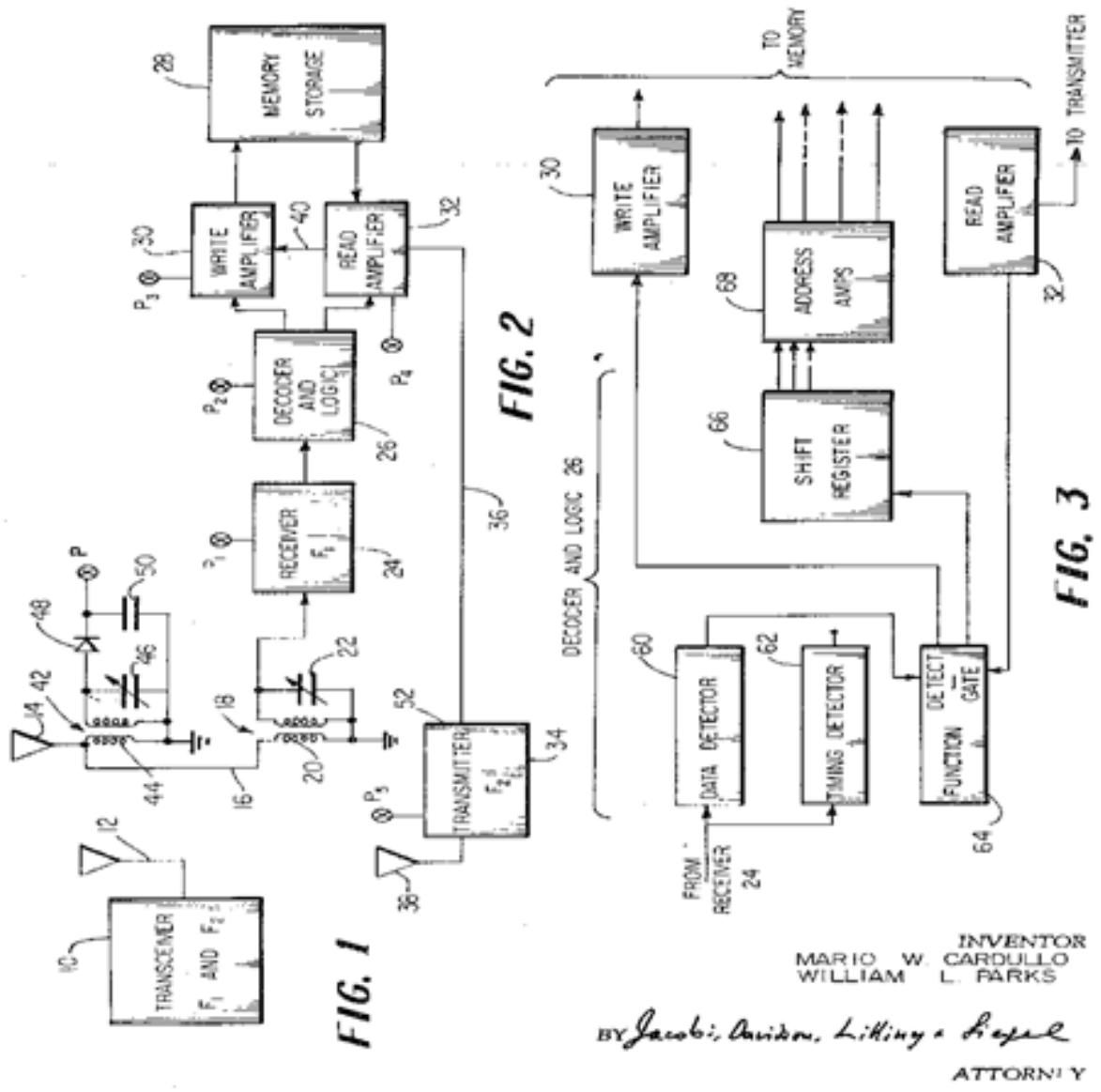

Source: M Cardullo, W. P. (1970). USA Patent No. US3713148 A 


\section{Exhibit 5: RFID Tool Management - CribMaster and Motion Industries}
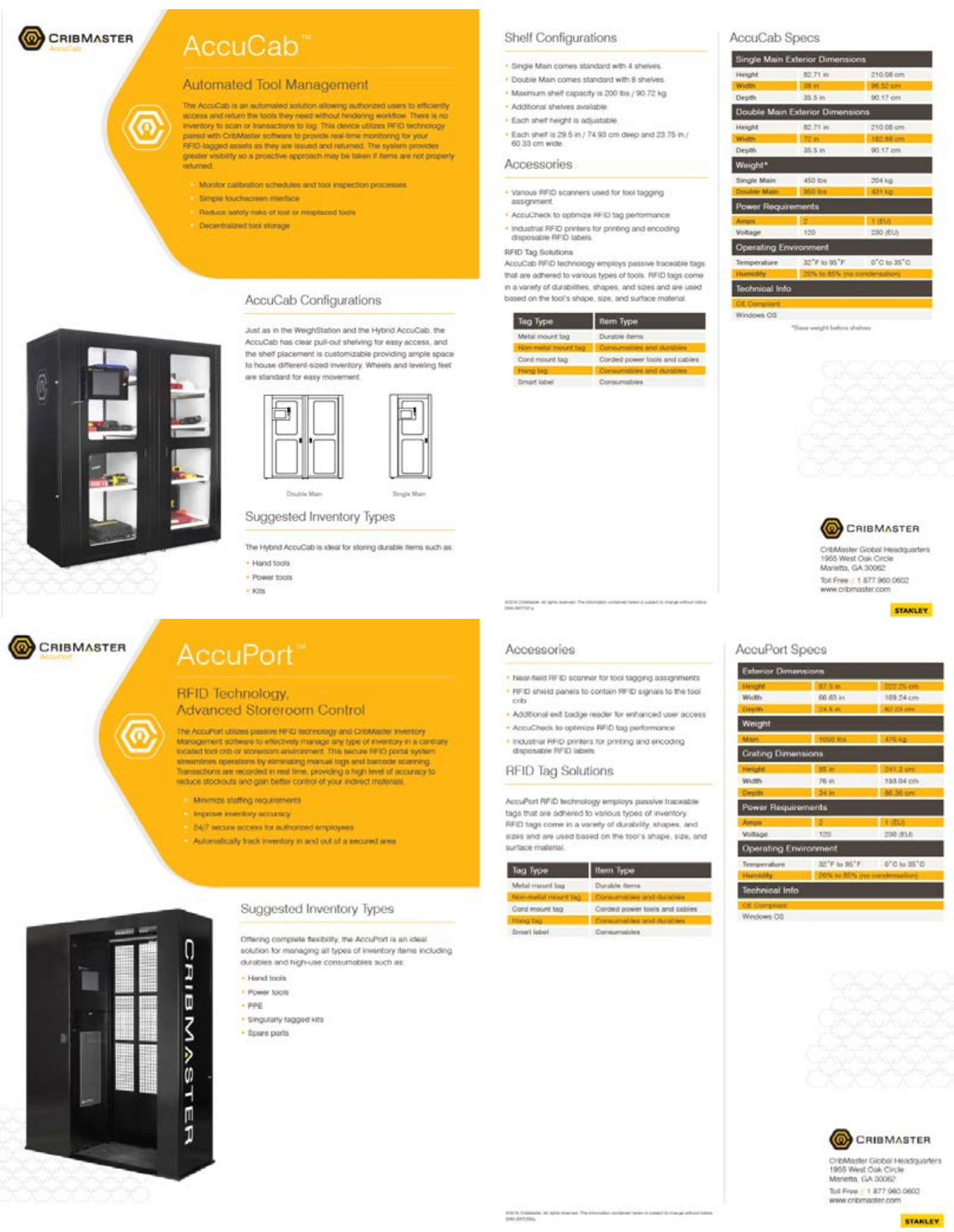

Source: http://www.cribmaster.com/solutions/rfid 


\section{IIII VENDING RFID STOREROOM * (2) 0}

\section{ADVANTAGES}

= Improve MRO inventory accuracy without changing culture

= Require log-in and secure gated entry

= Track by default cost centers or require selection prior to entry

= Automate the reorder process

= Opportunity to reallocate resources

- Gain control and accountability on 2nd and 3rd shift and weekends

= Off-the-shelf system easily deployable

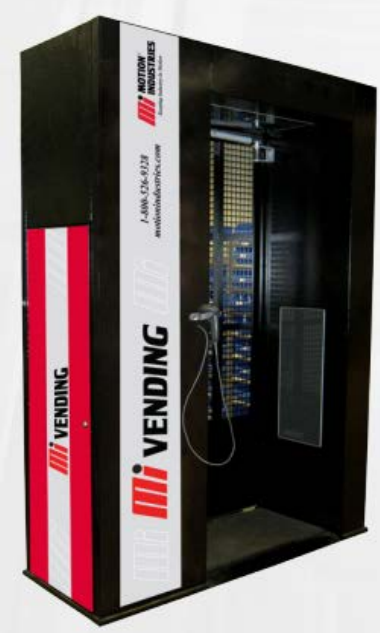

\section{IIII VENDING SELECTION MATRIX}

Not all vending machines are created equal

\begin{tabular}{|l|c|c|c|c|}
\hline \multicolumn{3}{|c|}{ COIL } & CAROUSEL & SCALE \\
\hline DEVICE TYPE & Very High & Very High & Medium & High \\
\hline Security/Control & Yes & Yes & No & Yes \\
\hline Single Item/QTY Access & 70 & 560 & 168 & None \\
\hline Max SKU & Yes & None & None & Easy \\
\hline Requires Repackaging & Easy & Very Easy & Complex & Yes \\
\hline Ease of Reconfiguration & No & Yes & Yes & Flexible \\
\hline Item Return Capability & Limited & Very Flexible & Very Flexible & \\
\hline Product Flexibility & \multicolumn{3}{|c|}{} \\
\hline
\end{tabular}

Source: https://www.motionindustries.com/motion3/jsp/mii/pdf/414_Mi_Vending_Brochure_RGB.pdf 
HENDRICKSON, HESS, JOSEPH, NANKERVIS, STONE

Exhibit 6: Mosaic RFID Effectiveness for Inventory Counts

\section{RFID Effectiveness for Inventory Counts}

\begin{tabular}{|c|c|c|c|c|}
\hline $\begin{array}{l}\text { Items } \\
\text { Counted }\end{array}$ & Mathod & People & TIME & Aceuraty \\
\hline 10,000 & Manual & 2 & $4-5$ Weeks & $65 \%$ \\
\hline 10,000 & Bar Code & 2 & 2.3 Weeks & $90 \%$ \\
\hline 10,000 & AFID & 2 & 2 Hours & $95 \%+4$ \\
\hline
\end{tabular}

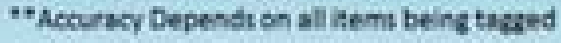

Source: Mosaic Company, JoAnn Speaks 


\section{Exhibit 7: Project and Option Costs}

- Vending:

o There was no cost to the end user as the machines are owned by the vendor. Machine type is determined by vendor based on items to be vended. The number of machines was typically based on revenue generation. For example, Motion Industries would supply 15 configured machines for every $\$ 1 \mathrm{mil}$ in revenue generated by items placed in those machines annually.

- Personnel:

0 Average hourly rate for warehouse/inventory personnel was $\$ 15 / \mathrm{hr}$ straight time and $\$ 22.50 /$ hr overtime. Based on a 45 hour work week and working 50 weeks per year, that comes to $\$ 35,625 / y r$. Taking into account that the average cost of benefits and other administrative costs was $35 \%$ of annual pay, then that annual cost goes up to $\$ 48,000 /$ yr/employee.

o Each site required 4 additional personnel, on average, if the current system was maintained to cover the issues identified. Therefore, yearly cost for increases in personnel were $\$ 192,000$.

- RFID equipment and supplies:

o Chemical site equipment package cost was $\$ 220,000$ per site. This did not include warehouse redesign and equipment installation which averaged $\$ 180,000$ per site.

o The minimal mining site equipment package cost for mine implementation was $\$ 120,000$. There was no requirement for redesign and installation cost were approximately $\$ 20,000$.

o Durable passive tags cost was \$15-25 each with an annual spend of approximately $\$ 6,000$.

o Passive printed labels cost was $\$ 750$ per roll of 2,500 with an annual spend of approximately $\$ 26,000$. 